TITLE:

\title{
Combined Failure Mechanism of a Breakwater Subject to Tsunami during 2011 East Japan Earthquake
}

$\operatorname{AUTHOR}(\mathrm{S}):$

lai, Susumu

\section{CITATION:}

Iai, Susumu. Combined Failure Mechanism of a Breakwater Subject to Tsunami during 2011 East Japan Earthquake. Geotechnical, Geological and Earthquake Engineering 2015, 37: $177-186$

ISSUE DATE:

2015-04-16

URL:

http://hdl.handle.net/2433/198459

\section{RIGHT:}

The final publication is available at Springer via http://dx.doi.org/10.1007/978-3-31910786-8_8; 許諾条件により本文ファイルは2016-04-16に公開.; This is not the published version. Please cite only the published version.; この論文は出版社版でありません。引用 の際には出版社版をご確認ご利用ください。 
Combined Failure Mechanism of a Breakwater Subject to Tsunami during 2011 East Japan Earthquake

Susumu Iai

Professor, Disaster Prevention Research Institute, Kyoto University, Japan

\begin{abstract}
In this study, a centrifuge model tests and effective stress analyses are performed on a breakwater subject to Tsunami such as those serious damaged during 2011 East Japan Earthquake (Magnitude 9.0). The centrifuge model tests at a scale of $1 / 200$ are performed to simulate the failure of a breakwater subject to Tsunami. With the effective stress analyses, this study demonstrates the importance of the mechanism of failure in the rubble mound due to seepage flow of pore water in addition to the force of Tsunami action.
\end{abstract}

Keywords: breakwater, failure mechanism, Tsunami, seepage flow

\title{
INTRODUCTION
}

An earthquake with a Japan Meteorological Agency (JMA) magnitude 9.0 hit north east Japan at 14:46, March 11, 2011. JMA named this earthquake '2011 Tohoku-Pacific Ocean earthquake'. This earthquake is the greatest in its magnitude since the modern earthquake monitoring system was established in Japan.

Recorded heights of the tsunamis were higher than $7.3 \mathrm{~m}$ at Soma, higher than $4.2 \mathrm{~m}$ at Oarai, and higher than $4.1 \mathrm{~m}$ at Kamaishi. The impact of the tsunamis is also the greatest since the existing design methodology was adopted for designing breakwaters. The existing design methodology of a breakwater is based on limit equilibrium by considering wave force acting from the lateral side and additional pressure acting underneath the caisson as shown in Figure 1.

The most typical example of the damage to breakwater was the one at the Kamaishi Harbor. In this example, the breakwater was specifically designed for protection against the impact of tsunami and constructed at the mouth of the Kamaishi harbor at a depth of $63 \mathrm{~m}$ or less over the length of $990 \mathrm{~m}$ in the northern part and $670 \mathrm{~m}$ in the southern part 
with an opening of $300 \mathrm{~m}$ in between. However, the breakwater was devastated by the tsunami. This may be partly due to the failure of design procedure then adopted but also a symbolic event for indicating the serious impact by the tsunami.

Figure 2 shows a typical cross section of the break water. The breakwater is a composite of caisson and rubble mound. Based on the visual data (video) monitored from the coastal line, the first arrival of the tsunami was at about 15:24 (about 40 minutes after the earthquake). The break water was not damaged by this first arrival of the tsunami.

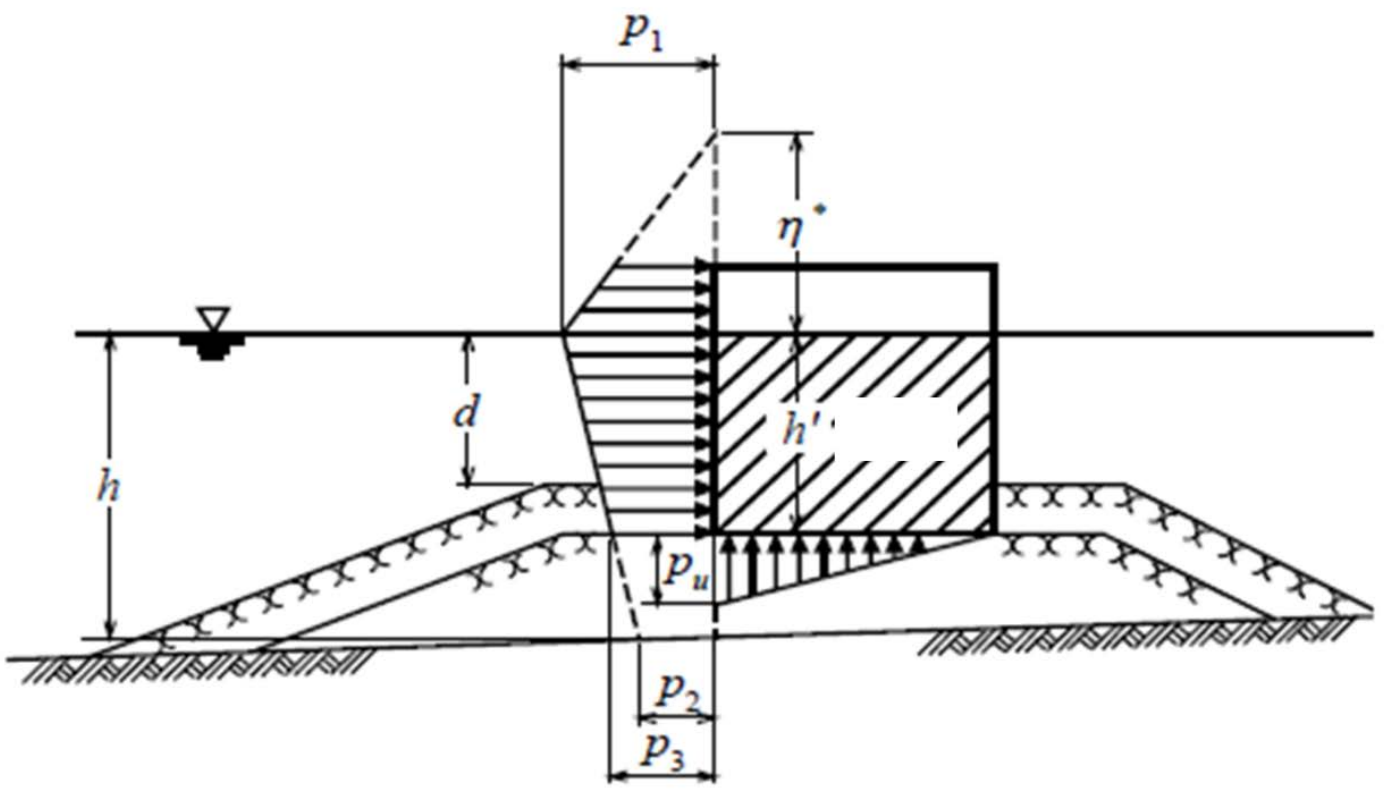

Figure 1 Existing design procedure of a breakwater

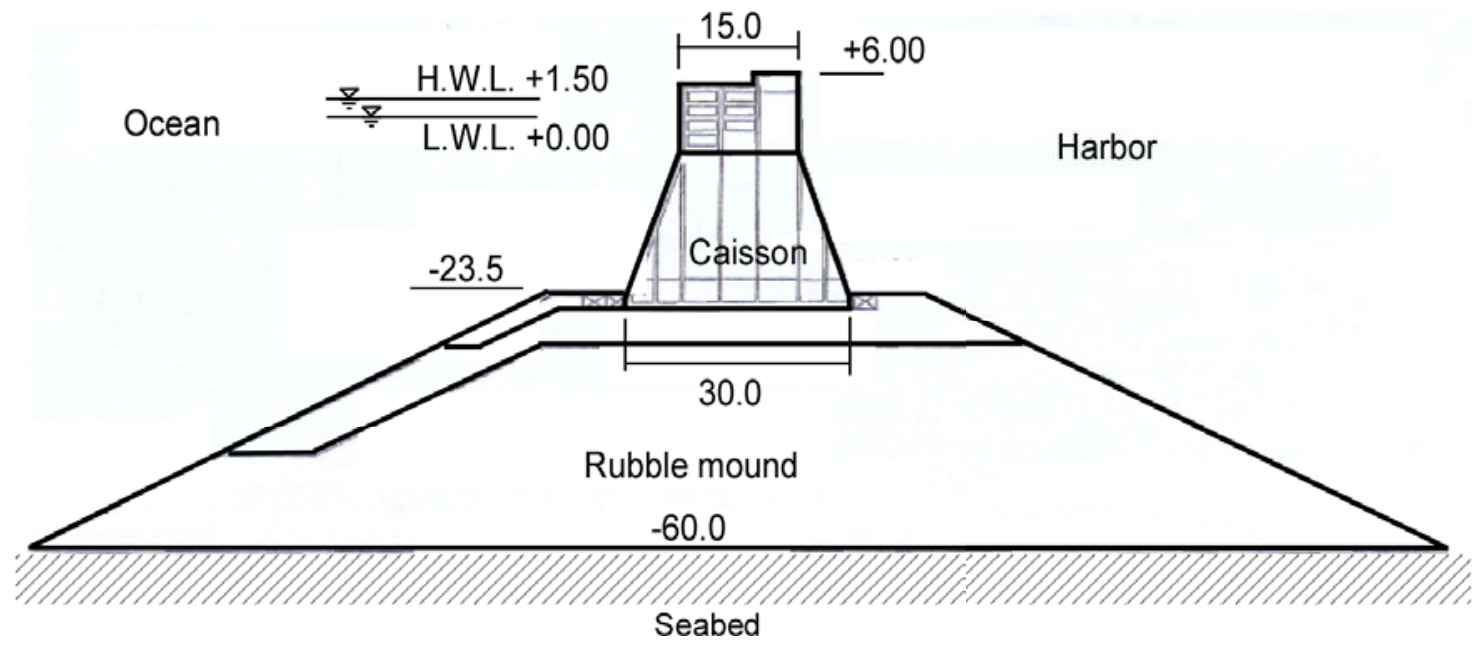

Figure 2 Cross section of a composite breakwater at Kamaishi Harbour (unit in m) 
However, there was a continual overtopping of water at the top of the breakwater. At about 15:32, when the height of the tsunami was reduced, serious devastation of the breakwater was visually confirmed by the monitored visual data. At 15:59, the devastation was progressed further and many of the caissons fell into the harbor side from the rubble mound. The rubble mound was also seriously devastated even to the extent that about half of its original body of the rubble mound was lost.

In order to investigate the primary mechanism of failure of this type of a breakwater due to Tsunami, a series of centrifuge model tests and effective analyses are performed in this study. As a straight forward extension of the existing design procedure shown in Figure 1, the primary mechanism of failure was considered by a hydrodynamics expert group due to erosion of rubble mound by the water flow through opening between caissons as shown in Figure 3. As parallel efforts to that group, this study was performed with the objective of evaluating the effect of seepage flow through the rubble mound due to water head difference due to Tsunami in combination with the wave force action.

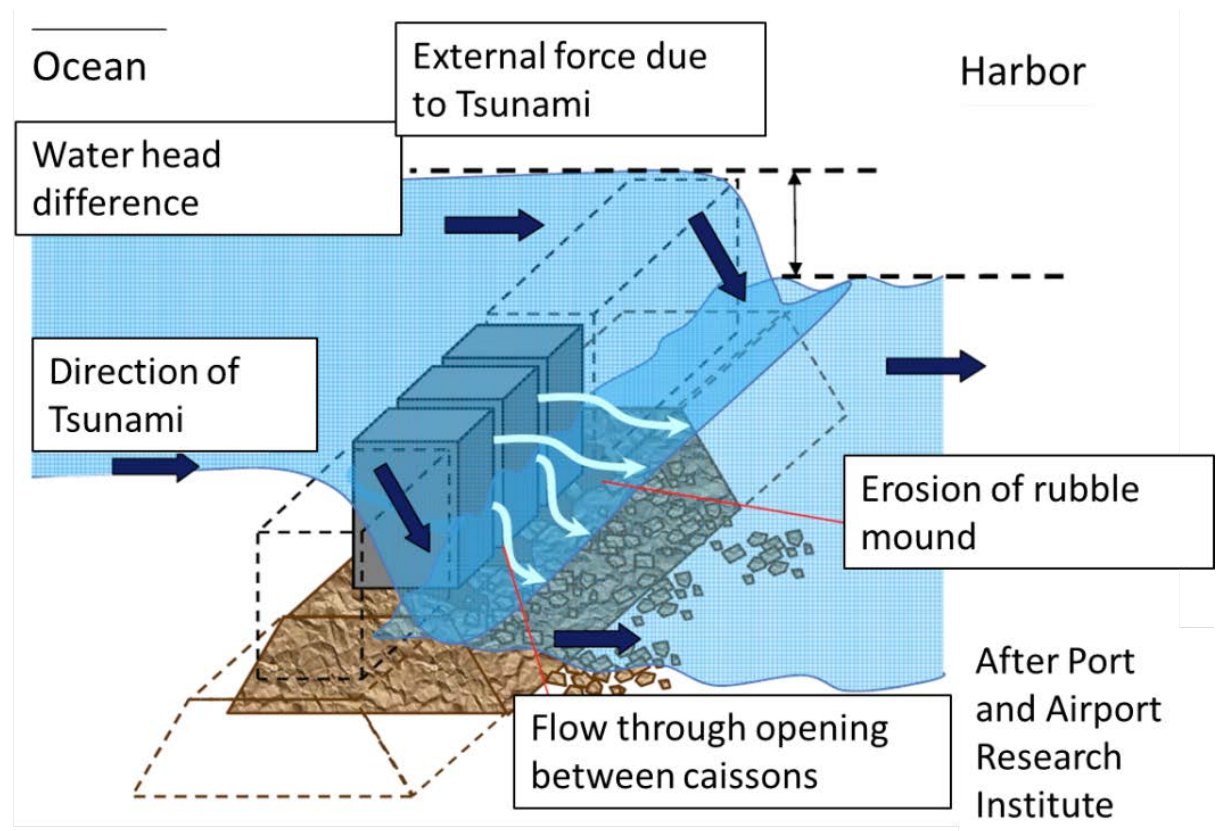

Figure 3 Primary mechanism of failure hypothesized by a hydrodynamics expert group

\section{CENTRIFUGE MODEL TESTS}

Tsunami Generator in Centrifuge and Model Test Conditions 
The centrifuge at Disaster Prevention Research Institute, Kyoto University, (effective radius $2.5 \mathrm{~m}$ ) was used for the centrifuge model tests in this study. The equipment for simulating Tsunami in the centrifuge is shown in Figure 4. In this equipment, the remote-control valve at the bottom of the water tank is opened for generating Tsunami-like water flow toward caisson and overflowing water at the other end of the model (left in this figure) is absorbed in a tentative storage pit for reducing the effect of reflecting wave from the (left side) wall of the container.

The centrifuge model tests were performed for a caisson $21 \mathrm{~m}$ high in prototype with a scaling factor of $1 / 200$ by adopting the generalized scaling relation (Iai et al. 2005) in a $25 \mathrm{~g}$ centrifugal acceleration field. Four cases were performed by varying initial sea water level and water level difference due to Tsunami as shown in Table 1. The material of rubble mound was also varied by using Silica No.1 sand that consists of particles scaled in 1/200 of the prototype rubble and Silica No.4 sand that artificially reduces the effect of seepage flow in the rubble mound. Pure water was used for centrifuge tests. The rubble mound model was made by water pluviation.

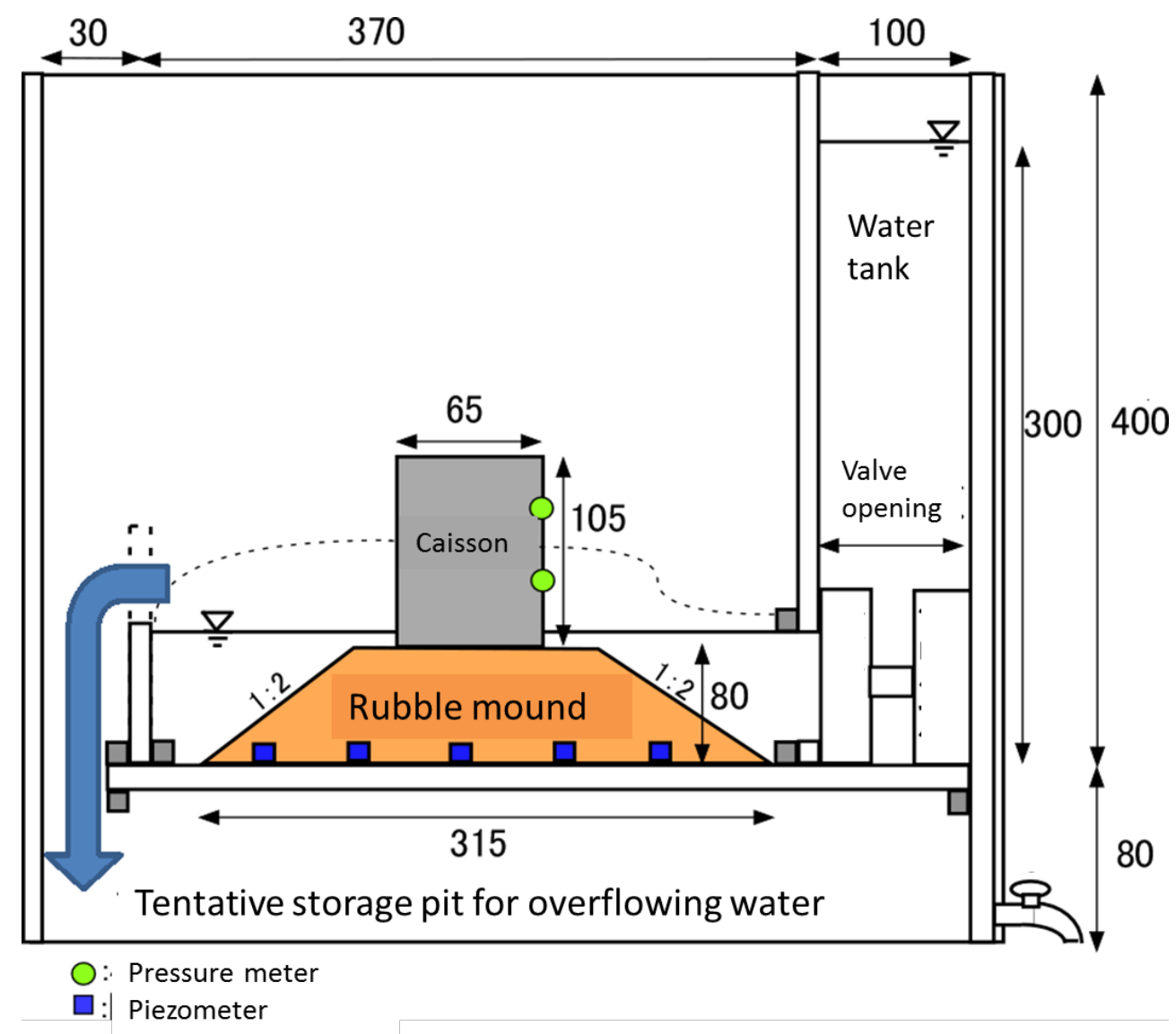


Figure 4 Equipment for simulating Tsunami in centrifuge model tests (unit in $\mathrm{mm}$ in model scale)

Table 1 Model test cases

\begin{tabular}{|c|c|c|c|c|}
\hline Case & Mound & Relative density & Sea water level & difference \\
\hline Case 1 & Silica \#1 sand & $55.5 \%$ & $6.23 \mathrm{~m}$ & $14.4 \mathrm{~m}$ \\
\hline Case 2 & Silica \#1 sand & $60.3 \%$ & $12.6 \mathrm{~m}$ & $10.3 \mathrm{~m}$ \\
\hline Case 3 & Silica \#4 sand & $58.0 \%$ & $8.15 \mathrm{~m}$ & $15.2 \mathrm{~m}$ \\
\hline Case 4 & Silica \#4 sand & $65.8 \%$ & $13.0 \mathrm{~m}$ & $10.9 \mathrm{~m}$ \\
\hline
\end{tabular}

Centrifuge Test Results

Figure 5 shows the results of the centrifuge test for Cases- 2 and 4 with respect to the deformation. As described earlier, Case-2 was performed for simulating the prototype condition. As shown in (a-1) in this figure, when the Tsunami at the water level difference of $10.3 \mathrm{~m}$ acts on the caisson, the caisson remains standing without deformation. At the same time, bubbles appear on the bay side (left side), indicating that a seepage flow of water through the rubble mound begins at this instance. After a certain period of time ((a-2) in the same figure), rubble mound gradually deforms in a bearing capacity failure mode with inclined load together with the caisson toward the direction of Tsunami wave force. The caisson eventually falls down from the rubble mound and the rubble mound exhibits a residual failure mode that resembles the classic circular failure mode.

These failure modes of the caisson and the rubble mound are consistent with those investigated and identified at Kamaishi Harbour after 2011 East Japan earthquake. This fact is indicative of the fact that the mechanism of failure due to tsunami is considered due to the combined effect of seepage flow and wave action. However, the mechanism of erosion progressing from the harbor side also produces the similar failure mode. Thus, the mechanism of failure has to be studies further by performing effective stress analysis as described later.

Case- 4 was performed as comparison to Case-2 by artificially reducing the effect of seepage flow in the rubble mound. Even if artificially reduced, the effect of seepage flow still exists so that a combined failure mode is also observed as shown in (b-1) 
through (b-3) in Figure 5. However, the failure mode in Case-4 is more or less dominated by sliding of caisson rather than deep failure mode of rabble mound. This fact indicate that if there is no seepage flow, then sliding failure mode will be dominant as often considered in the existing design procedure described earlier.
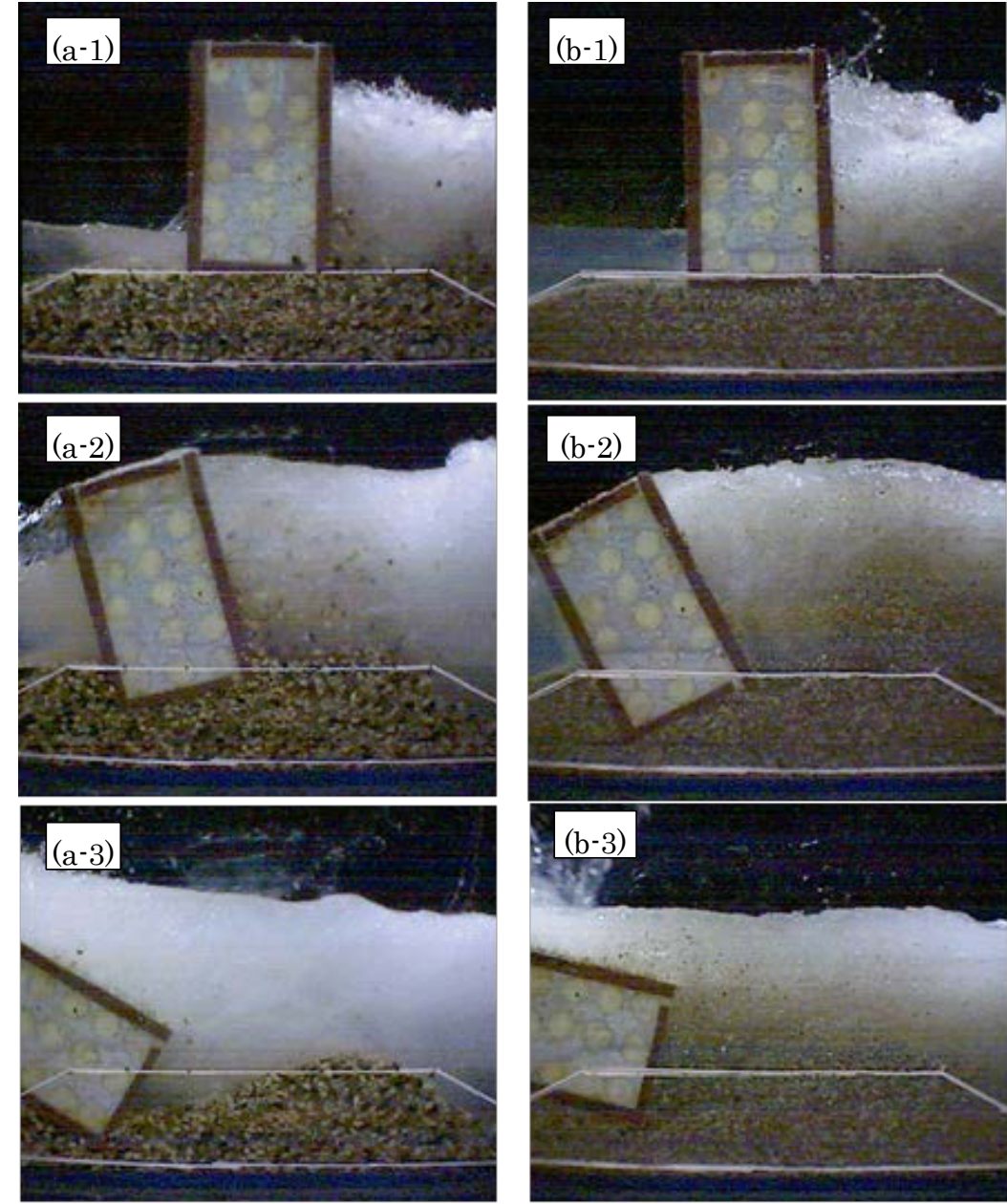

(a) Case-2

(b) Case-4

Figure 5 Deformation of caisson and rubble mound model

\section{EFFECTIVE STRESS ANALYSIS}

Effective Stress Model

For the effective stress analysis of a breakwater subject to seepage flow and wave action, the strain space multiple mechanism model with a cocktail glass model is used (Iai et al. 2011). In the strain space multiple mechanism model, the effective stress, defined as 
extension positive, is given based on a dyad defined by the unit vector $\mathbf{n}$ along the direction of the branch between the particles in contact with each other and the unit vector $\mathbf{t}$ normal to $\mathbf{n}$ as follows:

$$
\begin{gathered}
\boldsymbol{\sigma}^{\prime}=-p \mathbf{I}+\frac{1}{4 \pi} \iint q\langle\mathbf{t} \otimes \mathbf{n}\rangle \mathrm{d} \omega \mathrm{d} \Omega \\
\langle\mathbf{t} \otimes \mathbf{n}\rangle=\mathbf{t} \otimes \mathbf{n}+\mathbf{n} \otimes \mathbf{t}
\end{gathered}
$$

where $p$ denotes effective confining pressure (compression positive), I denotes second order identity tensor, $q$ denotes micromechanical stress contributions to macroscopic deviator stress due to virtual simple shear mechanism (called virtual simple shear stress), and $\langle\mathbf{t} \otimes \mathbf{n}\rangle$ denotes second order tensor representing the virtual simple shear mechanism. Out of the double integration, the integration with respect to $\omega(=0$ through $\pi)$ is taken over a virtual plane spanned by the direction vectors $\mathbf{n}$ and $\mathbf{t}$ with $\omega / 2$ being the angle of $\mathbf{n}$ relative to the reference local coordinate defined in the virtual plane, while the integration with respect to the solid angle $\Omega$ is taken over a surface of a unit sphere to give a three dimensional average of two dimensional mechanisms.

The integrated form of the constitutive equation, i.e. direct stress strain relationship, is derived by relating the macroscopic strain tensor $\boldsymbol{\varepsilon}$ to the macroscopic effective stress $\boldsymbol{\sigma}^{\prime}$ through the structure defined by Equation (1). The first step to derive this relationship is to define the volumetric strain $\varepsilon$ (extension positive) and the virtual simple shear strains $\gamma$ as the projections of the macroscopic strain field to the second order tensors representing volumetric and virtual simple shear mechanisms as follows:

$$
\begin{gathered}
\varepsilon=\mathbf{I}: \boldsymbol{\varepsilon} \\
\gamma=\langle\mathbf{t} \otimes \mathbf{n}\rangle: \boldsymbol{\varepsilon}
\end{gathered}
$$

where the double dot symbol denotes double contraction. In order to take into account the effect of volumetric strain due to dilatancy $\varepsilon_{\mathrm{d}}$, effective volumetric strain $\varepsilon^{\prime}$ is introduced by

$$
\varepsilon^{\prime}=\varepsilon-\varepsilon_{\mathrm{d}}
$$

where the rate of volumetric strain due to dilatancy is given by the projection of strain rate field to a second order tensor $\mathbf{I}_{\mathrm{d}}$ as

$$
\dot{\varepsilon}_{\mathrm{d}}=\mathbf{I}_{\mathrm{d}}: \dot{\boldsymbol{\varepsilon}}
$$


The scalar variables defined in Equations (4) and (5) as the projection of macroscopic strain field are used to define the isotropic stress $p$ and virtual simple shear stress $q$ in Equation (1) through path dependent functions as

$$
\begin{gathered}
p=p\left(\varepsilon^{\prime}\right) \\
q=q(\gamma)
\end{gathered}
$$

In the strain space multiple mechanism model, the virtual simple shear mechanism is formulated as a non-linear hysteretic function, where a back-bone curve is given by the following hyperbolic function;

$$
q(\gamma)=\frac{\gamma / \gamma_{\mathrm{v}}}{1+\left|\gamma / \gamma_{\mathrm{v}}\right|} q_{\mathrm{v}}
$$

The parameters $q_{\mathrm{v}}$ and $\gamma_{\mathrm{v}}$ defining the hyperbolic function are the shear strength and the reference strain of the virtual simple shear mechanism, respectively.

The isotropic component in Equation (7) is defined by a hysteretic tangential bulk modulus depending on the loading/unloading (L/U) condition as

$$
K_{\mathrm{L} / \mathrm{U}}=-\frac{\mathrm{d} p}{\mathrm{~d} \varepsilon^{\prime}}=r_{K} K_{\mathrm{U} 0}\left(\frac{p}{p_{0}}\right)^{l_{K}}
$$

where $p_{0}$ : initial confining pressure, $K_{\mathrm{U} 0}$ : tangential bulk modulus at initial confining pressure.

Dilatancy in Equation (5) in the Cocktail glass model is decomposed into contractive component $\varepsilon_{d}^{c}$ and dilative component $\varepsilon_{d}^{d}$ as

$$
\varepsilon_{\mathrm{d}}=\varepsilon_{\mathrm{d}}^{\mathrm{c}}+\varepsilon_{\mathrm{d}}^{\mathrm{d}}
$$

However, in this study, effect of dilatancy of the rubble mound was assumed negligibly small and dilatancy was ignored.

\section{Load Conditions for Simulating Tsunami}

The effective stress analysis of a breakwater was performed for prototype scaled from the centrifuge model, including a caisson 21m high. As shown in Figure 6, joint element is specified at the bottom of the caisson to allow sliding and separation between the 
caisson and the rubble mound. After static gravity analysis to set the initial conditions for dynamic Tsunami analysis, Tsunami wave force was applied on the caisson as equivalent static distributed force as shown in Figure 7. In order to analyze the effect of seepage flow due to sea level difference, excess pore water pressure was applied at the rubble mound. External force due to sea level difference is also simulated by equivalent lateral static force on the caisson.

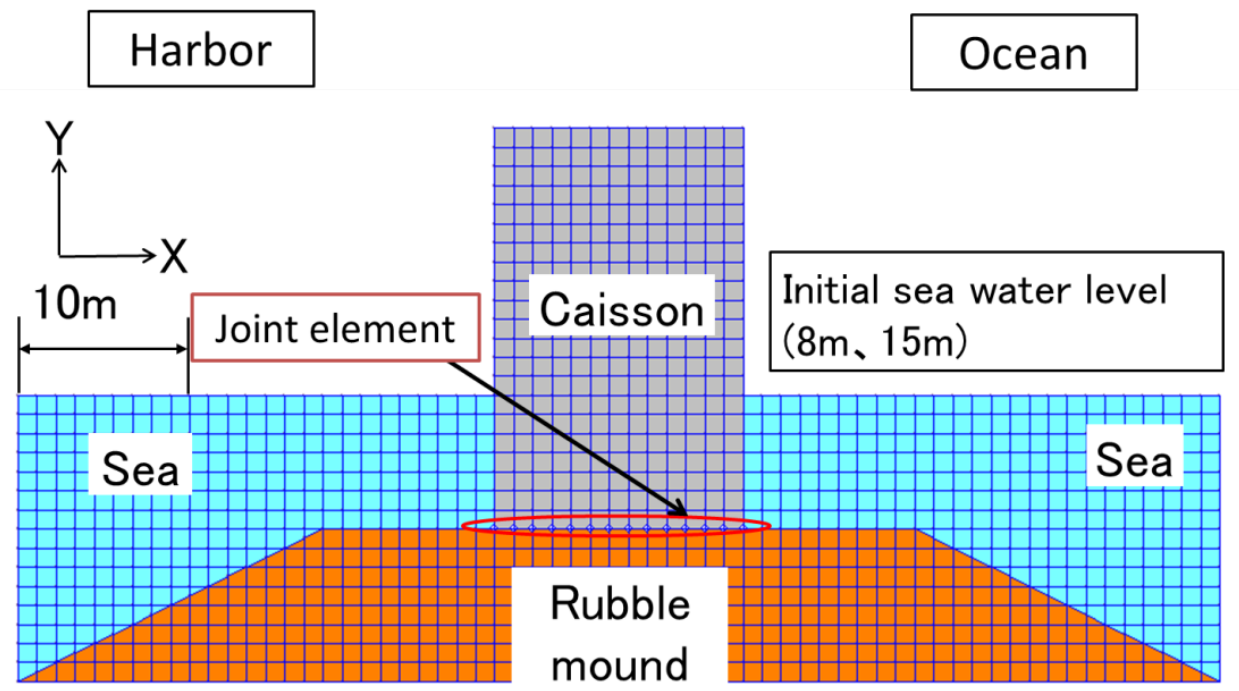

Figure 6 Finite element mesh of a breakwater for analysis (prototype scale)
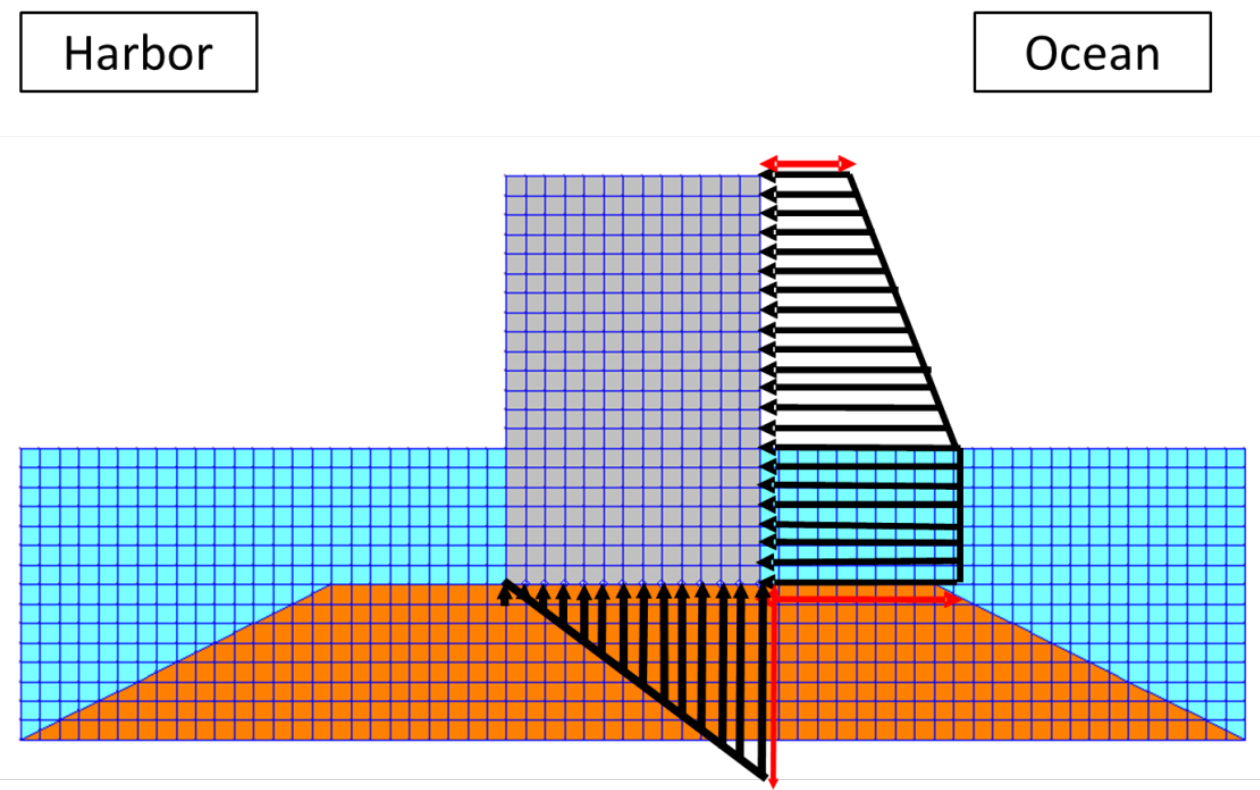

Figure 7 Load conditions for simulating wave force due to Tsunami 
Distribution and magnitude of the wave force due to Tsunami adopted for the analysis (Figure 7) was determined based on the proposal by Tanimoto et al (1984). This proposal has been also adopted in the existing design procedure of a breakwater (Figure 1).

The effective stress analyses were performed for Cases- 1 through 4 with the material parameters used for the rubble mound shown in Table 2. These parameters were determined by undrained cyclic shear tests using hollow cylinder specimen and by permeability test with constant water level difference. The initial sea levels for Cases-1 through 4 were simplified for the analysis as shown in Figure 6. The sea level differences were also simplified as $15 \mathrm{~m}$ for Cases-1 and 3, and 11m for Cases-2 and 4.

Table 2 Material parameters of rubble mound

\begin{tabular}{|c|c|c|c|c|c|}
\hline mound & density & permeability & shear modulus & $\phi f$ & cohesion \\
\hline Silica \#1 & $1.91(\mathrm{t} / \mathrm{m} 3)$ & $7.06 \times 10^{-2}(\mathrm{~m} / \mathrm{s})$ & $6.15 \times 10^{4}(\mathrm{kPa})$ & $40.8^{\circ}$ & $0(\mathrm{kPa})$ \\
\hline Silica \#4 & $1.90(\mathrm{t} / \mathrm{m} 3)$ & $1.56 \times 10^{-3}(\mathrm{~m} / \mathrm{s})$ & $7.67 \times 10^{4}(\mathrm{kPa})$ & $38.7^{\circ}$ & $\mathrm{O}(\mathrm{kPa})$ \\
\hline
\end{tabular}

Results of the Effective Stress Analyses

The results of analysis of Case-2 are presented below. Figure 8 (a) shows residual deformation of a breakwater with both Tsunami wave force on the caisson and seepage flow in the rubble mound. The tilting of the caisson is associated with a significant deformation of rubble mound. This mode of failure is consistent with that observed at the centrifuge model test. In comparison to this result, deformation of a breakwater due to Tsunami wave force only is negligibly small as shown in Figure 8 (b). These results of the analyses indicate that primary mechanism of failure of a breakwater due to Tsunami is combined failure mechanism due to Tsunami wave force and seepage flow in the rubble mound due to water level difference associated with Tsunami.

In addition, distribution of an inverse of safety factor with respect to Mohr-Coulomb failure criterion in the rubble mound is shown in Figure 9. As shown in Figure 9(a), the rubble mound beneath the caisson undergoes a compression shear due to the overburden from the caisson before Tsunami. When the Tsunami wave force and seepage flow act on the rubble mound, significant area of cross section of rubble mound are brought close to a shear failure condition as shown in Figure 9(b). However, if only the Tsunami 
wave for acts, there is not a significant change in the rubble mound with respect to its stress status. These results also supports the previous notion that the primary mechanism of failure of a breakwater due to Tsunami is combined failure mechanism involving seepage flow in the rubble mound.

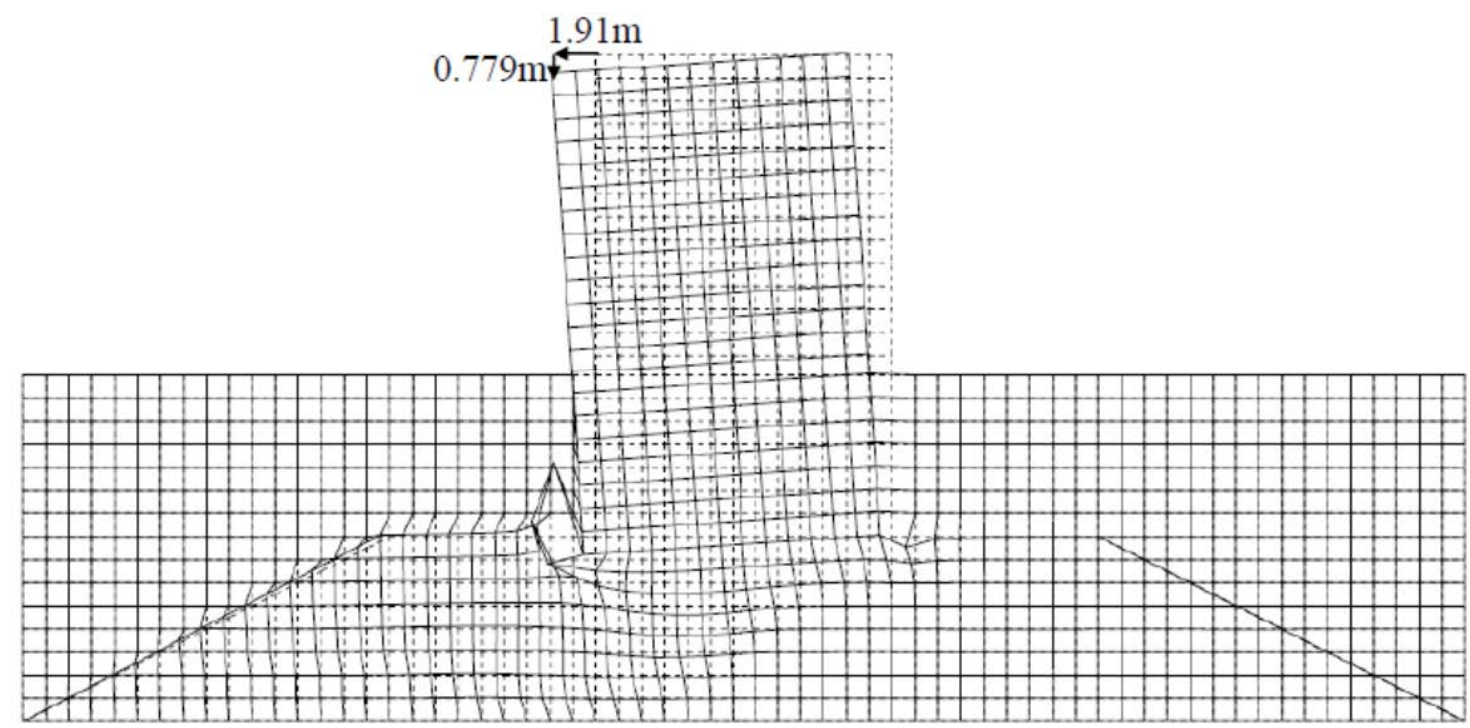

(a) Analysis with wave force and seepage flow

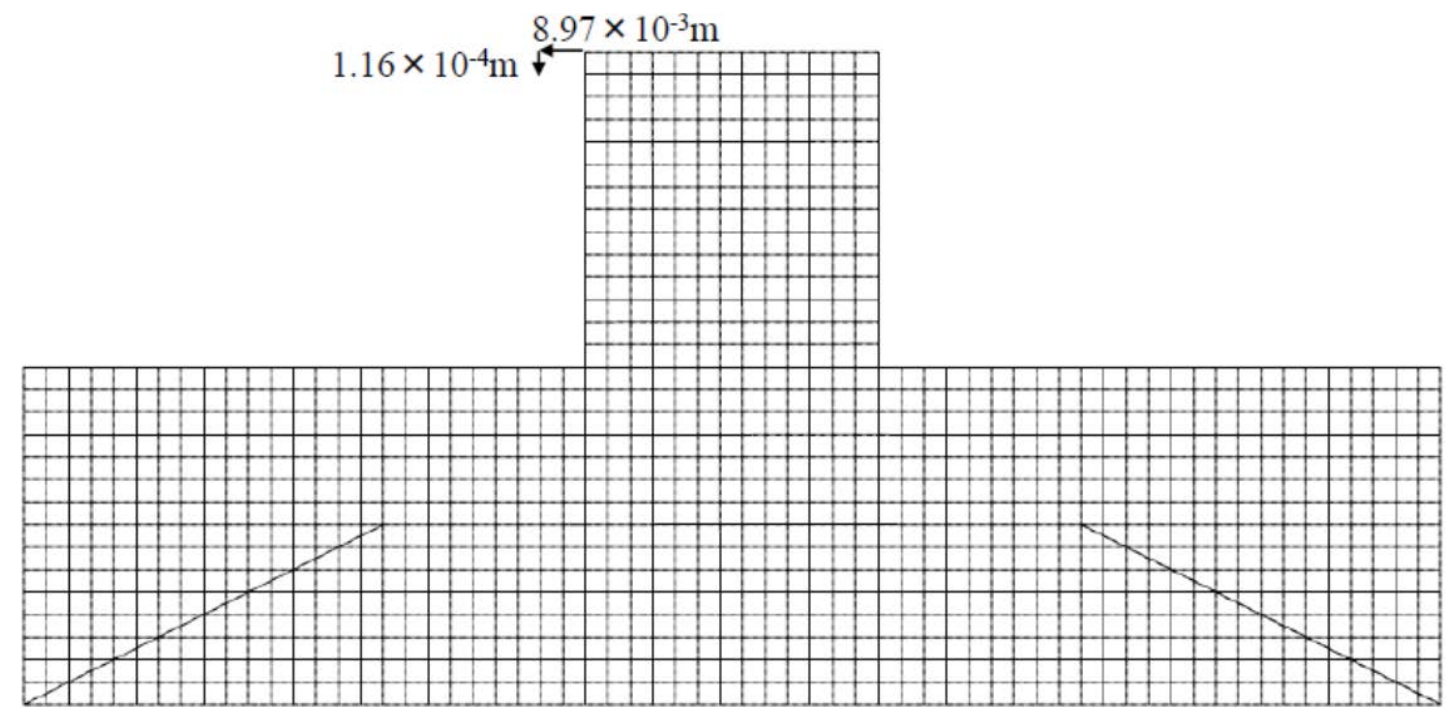

(b) Analysis with wave force only

Figure 8 Residual deformation of a breakwater 


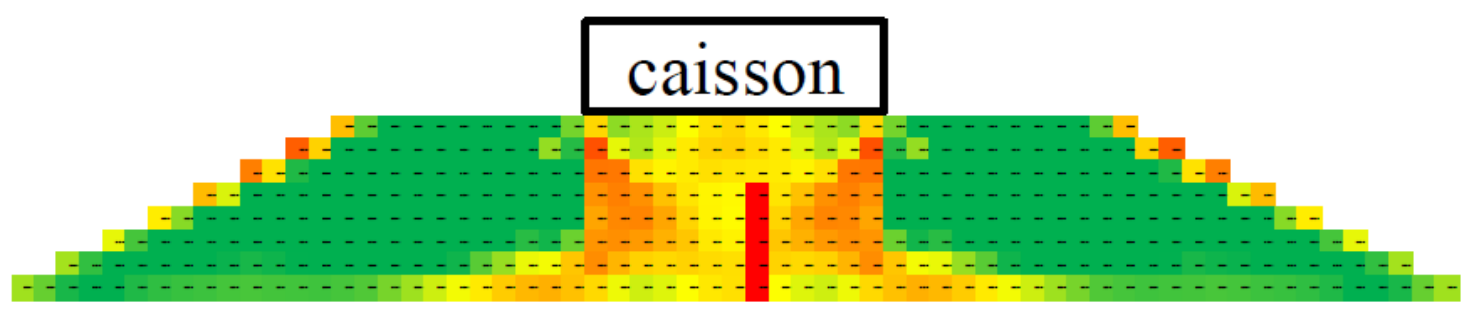

(a) Initial condition for dynamic analysis

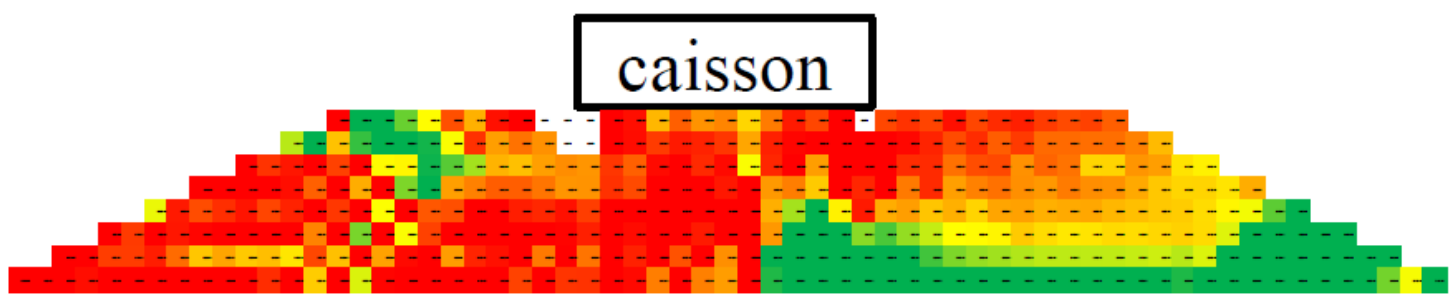

(b) Residual status due to Tsunami wave force and seepage flow

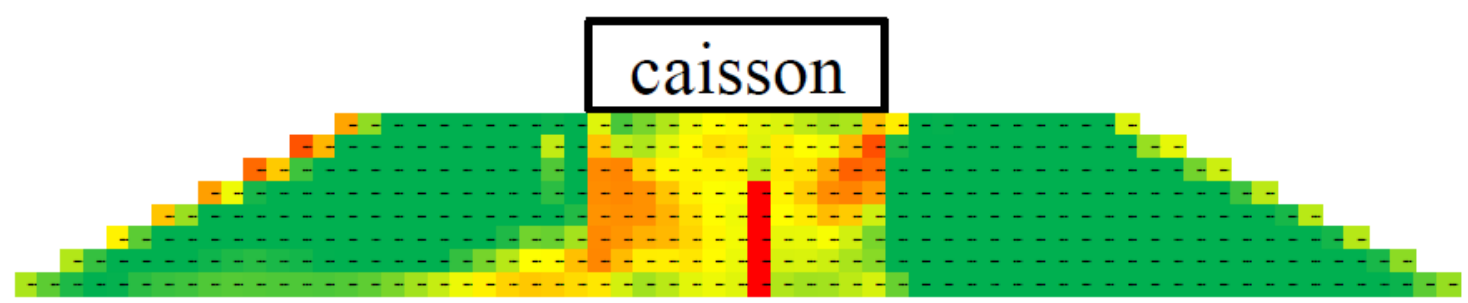

Index: 1/Safety Factor 0.8

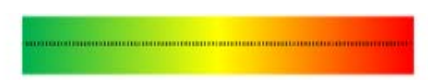

(c) Residual status due to Tsunami wave force only

Figure 9 Distribution of 1/Safety Factor in the rubble mound

\section{CONCLUSIONS}

In this study, a centrifuge model tests and effective stress analyses are performed on a breakwater subject to Tsunami such as those serious damaged during 2011 East Japan Earthquake (Magnitude 9.0). Both the centrifuge model tests at a scale of 1/200 and the effective stress analyses demonstrate the importance of the mechanism of failure in the rubble mound due to seepage flow of pore water in addition to the wave force of Tsunami action.

\section{REREFERENCES:}

Iai, S., Tobita, T. and Nakahara, T. (2005): Generalized scaling relations for dynamic centrifuge tests, Geotechnique, 55(5): 355-362. 
Iai, S., Tobita, T., Ozutsumi, O. and Ueda, K. (2011): Dilatancy of granular materials in a strain space multiple mechanism model, International Journal for Numerical and Analytical Methods in Geomechanics, 35(3): 360-392.

Tanimoto, K., Tsuruya, K., and Nakano, S. (1984): Tsunami wave force and failure mechanism of bulkhead due to Tsunami during 1983 Nihonkai-chubu earthquake, Proc. 31th Research Conference on Coastal Engineering, 257-261 (in Japanese) 